\title{
Design and implementation of automatic painting mobile robot
}

\author{
Amgad Muneer ${ }^{1}$, Zhan Dairabayev ${ }^{2}$ \\ ${ }^{1}$ Department of Computer and Information Sciences, Universiti Teknologi PETRONAS, Malaysia \\ ${ }^{2}$ School of Engineering, Asia Pacific University of Technology \& Innovation, Malaysia
}

\begin{abstract}
Article Info
Article history:

Received Jan 27, 2021

Revised Feb 9, 2021

Accepted Feb 24, 2021

\section{Keywords:}

Automatic painting robot

Building automation

Pulley mechanism

Robotics

Spray painting

ABSTRACT

Wall painting is a repetitive, stressful, and hazardous process that makes it an ideal automation case. In the automotive industry, painting had been automated but not yet for the construction industry. However, there is a strong need for a mobile robot that can move to paint residential interior walls. In this study, we aim to design and implement an automatic painting mobile robot. The conceptual design of the proposed wall painting robot consisting paint mechanism with a spray gun and ultrasonic sensor. The spray gun is attached to a pulley mechanism that has linear motion. The ultrasonic sensor is used to detect the spray gun when it reached a certain limit. The DC motor rotates clockwise and counterclockwise based on the ultrasonic sensor condition made. The experimental results indicate that the robot was able to paint the walls smoothly vertically, and horizontally. The spraying gun structure's speed is at a tolerable speed of $0.07 \mathrm{~m} / \mathrm{s}$, which could be increased, but to provide high-quality painting without any gaps, the current speed was selected as the most suitable, without any harm to the working process.
\end{abstract}

This is an open access article under the CC BY-SA license.

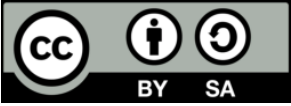

\section{Corresponding Author:}

\author{
Amgad Muneer \\ Department of Computer and Information Sciences \\ Universiti Teknologi PETRONAS \\ Seri Iskandar 32160, Malaysia \\ Email: muneeramgad@gmail.com
}

\section{INTRODUCTION}

Robots is one of the most widely used automation methods in a number of sectors, from heavy industry [1], healthcare and smart libraries [2,3]. The robot is an interdisciplinary technology to build robots that imitate and replace human beings, including mechanical engineering, electronic and electrical engineering, artificial intelligence, and computer vision [4]. The automatic wall painting robot has become a necessity in the past decade [5,6] due to the increase in the height of the buildings and more and more skyscrapers [7]. Much research and money are invested in finding a solution to this problem [8-10]. The solution would help to eliminate the loss of life due to the external factors acting when the workers are doing their job, such as high wind, storm and falls $[11,12]$. Nowadays, all the countries over the world are rapidly developing, each day rising hundreds of buildings. Painting walls is significant, and it is not just improving the interior. Also, it can be explained as a part of the building process [13]. However, according to Bureau of Labor Statistics, there were approximately 2.9 million nonfatal workplace injuries reported by private industry employers in 2015, which occurred at a rate of 3 cases per 100 equivalent full-time workers [14]. This number is growing each year, which is a global worldwide problem, and it must be solved.

Therefore, the main achievement to be reached in the current study is focused on developing a sustainable and reasonable priced wall painting automatic robot to increase the efficiency of wall painting and reduce the human power involved in current activity. The automatic machine should carry out a whole wall 
painting process to paint the wall without human involvement and a higher level of sufficient efficiency. A robot has an efficient working algorithm $[15,16]$, providing the world with an autonomous machine that will be able to: detect the area that needs to be painted [17], analyzes the surface throughout the developed software [18], paint the surface, checks on any empty spaces, and to do correction if needed. The remainder of this paper is organized as follows. Section 2 gives an overview of the methodology adopted for the proposed research and described the experimental model. Results are discussed in Section 3, while; the conclusion and the future work are given in Section 4.

\section{RESEARCH METHOD AND HARDWARE}

In the literature, most of the size of the robots are varies, it has a significant weight, is working slow, and the price is surprisingly high. Thus, it is not easily accessible for the people. To solve the problem that is stated as a danger to human life while painting process, the robot is designed to be suitable for the wall painting without taking any risk for human life. This study consists of two parts: One part, which is the basement of the robot, are represented as a board with four wheels, which are on the rooftop of the building. It is created to carry all the parts which are responsible for controlling the system, motor, battery, weight, and pressure bank for the spraying gun. It will also have "grips" to make the board stable while the painting process and stay steady to not fall down from the rooftop. The second part, which is the robot itself, will be represented as a longboard, with 4 wheels, with a movable spraying gun. Figure 1 shows the process of painting implemented in this study.

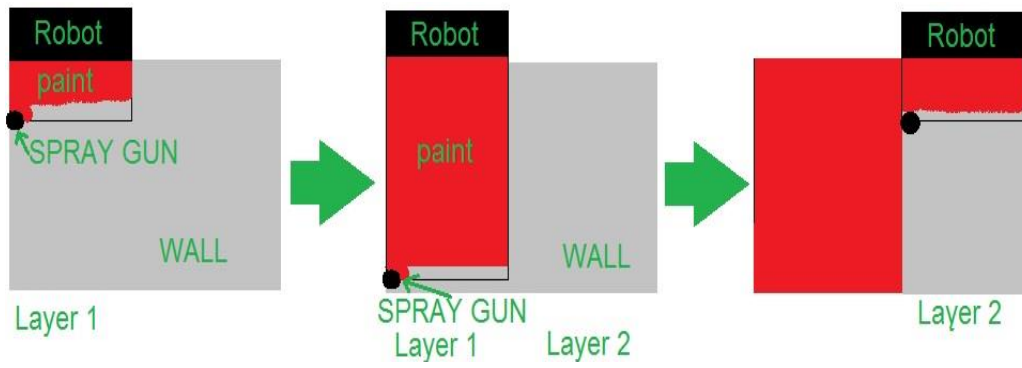

Figure 1. Process of painting

The proposed robot is an automotive mobile robot, but it will need human involvement in its working process. The robot will be painting walls from up to down, the worker will need to activate a motor for the metal ropes which are holding the robot, so it will be descended downwards when the painting process is done vertically, the worker on the rooftop will need to bring it up by activating the motor so it will pull robot upwards by ropes attached to it. The worker will move the basement of the robot on the rooftop horizontally and continue the painting process. This algorithm will be done multiple times until reaching the successfully painted selected area, as shown in Figure 2. However, to let the robot "know" how big the area for painting is, the worker will have to input the length and the width of the selected area after taking the measurements.

As the robot consists of two parts, it was decided to use 2 Arduino Uno microcontroller boards and connect them wirelessly so that when the mobile structure will be in the stage of wall painting, there will not be any need for long wires, connecting it to the base structure. This decision is also a good solution, and it affects a cost positively, making overall robot constructional priceless because there will not be any need in installing long wires, wire collecting coils. The robot's base structure consists of Arduino Uno microcontroller board, motor driver L298N, the puling mechanism (DC-motor, pulleys, nylon ropes), and $12 \mathrm{~V}$ DC battery a power supply, Arduino HC-05 serial port wireless transmitter module and wooden base construction itself.

Figure 3 shows the proposed automatic mobile robot's final hardware design with all mechanism and components used. The design shows there is two pulley mechanism and where they located. The pulley system placed on the top is to move the L-shape ups and downs with the help of the DC motor that can carry about 10 $\mathrm{kg}$. The other pulley mechanism is to move the spray gun left and right (linear motion) to paint the wall entirely. In the proposed hardware design, there are two Arduino Uno implemented. One is for master purpose and the other for slave purpose. Figure 4 shows the paint mechanism design with the spray gun and ultrasonic sensor. The spray gun is attached to a pulley mechanism with linear motion-the ultrasonic sensor used to detect the spray gun when it reached the specific limit. The DC motor rotates Clockwise and Counterclockwise based on the ultrasonic sensor condition made. 

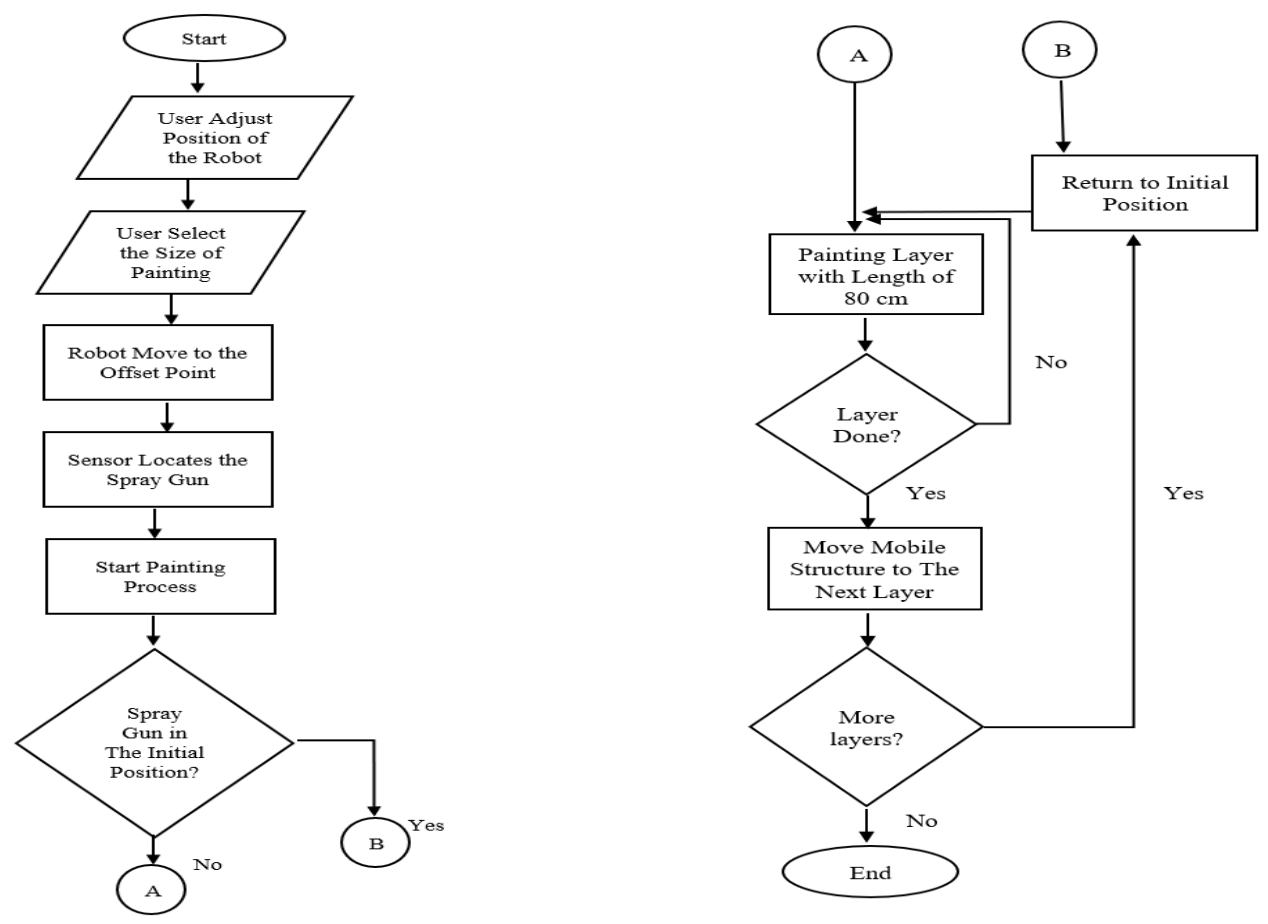

Figure 2. Proposed algorithm process

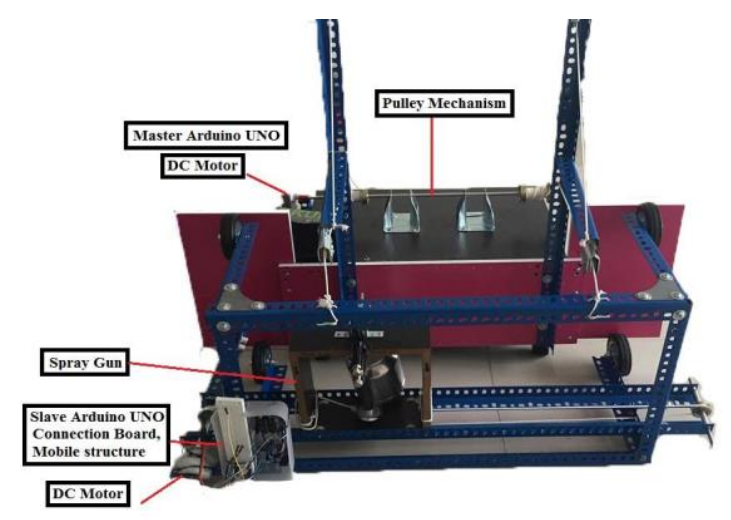

Figure 3. Photograph of the painting robot (Experimental model)

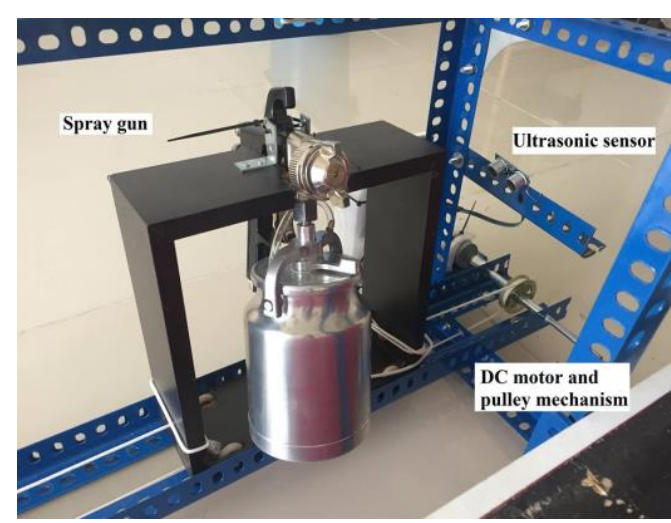

Figure 4. Paint mechanism design

\section{RESULTS AND DISCUSSION}

Several experiments were conducted to check the performance of the system. The purpose of testing the system is to ensure that the system is adequately evaluated. The following are the experiments conducted to evaluate the performance of the proposed wall painting robot:

\subsection{Time taken for vertical translation of mobile structure}

The experimental setup for the vertical translation was done by setting up the prototype's stationary module at the height of 5 meters. The mobile structure with the spray gun was hung freely and controlled by the Arduino microcontroller. The program was written to move the structure to varying levels of height. The heights were measured manually using a measuring tape, and the readings from the ultrasonic sensor were compared to the aforementioned actual readings. Thus, this is important because, during the prototype's actual application, the height should be measured very accurately for optimum performance. Table 1 shows the data for the vertical translation of the mobile part. The time taken for the translation was measured against the displacement. The test was done twice, and the mean value was calculated in order to increase accuracy and precision. 
Table 1. Time taken for vertical translation

\begin{tabular}{cccc}
\hline $\begin{array}{c}\text { Test1: } \\
\text { Time taken } \\
\text { (seconds) }\end{array}$ & $\begin{array}{c}\text { Test2: } \\
\text { Time taken } \\
\text { (seconds) }\end{array}$ & Average & $\begin{array}{c}\text { Distance } \\
\text { measured } \\
\text { (meters) }\end{array}$ \\
\hline 2.4 & 2.5 & 2.45 & 0.25 \\
4.9 & 4.9 & 4.9 & 0.50 \\
7.2 & 7.3 & 7.25 & 0.75 \\
9.5 & 9.6 & 9.55 & 1.00 \\
11.7 & 11.9 & 11.8 & 1.25 \\
14.0 & 14.2 & 14.1 & 1.50 \\
16.3 & 16.4 & 16.35 & 1.75 \\
18.5 & 18.5 & 18.5 & 2.00 \\
\hline
\end{tabular}

Figure 5 shows the time taken for the vertical displacement of 2 meters. The speed of the mobile part is at an adequate speed of roughly $0.1 \mathrm{~m} / \mathrm{s}$ for each cycle. This is an adequate speed for the painting to be done correctly. No acceleration was done because it would cause uneven coats of paint, which would result in the prototype having to do extra movement to complete the painting process. The vertical movement testing indicated that the overall vertical movement of the mobile part was linear and smooth. This was a good indication that the painting process would run smoothly.

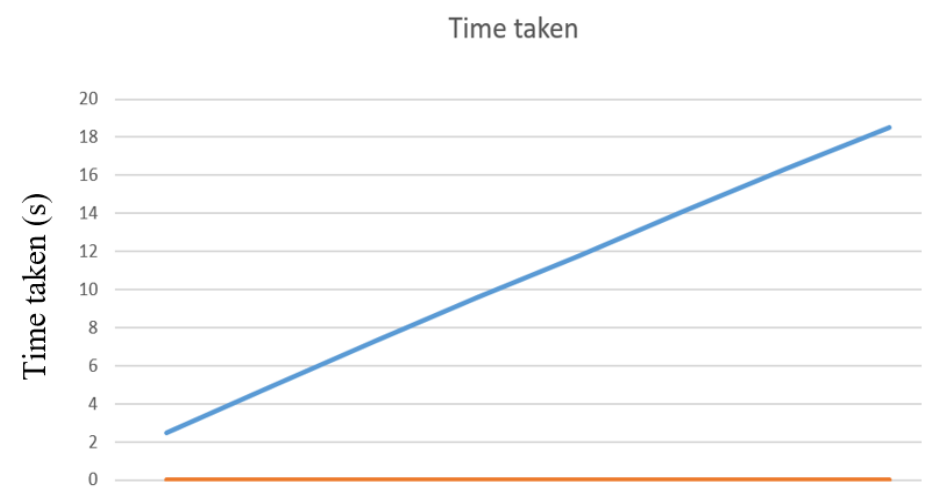

Distance $(\mathrm{m})$

Figure 5. Time taken for vertical translation

\subsection{Time taken for horizontal translation of paint spray gun}

The horizontal translation of the paint gun was tested by using the ultrasonic sensor. The displacement of the paint gun was tested in a manner like the vertical translation of the mobile part. The mobile part was set on the ground for this test. The total distance between the ultrasonic sensor and the paint spray gun at the furthest distance is 0.80 meters. It had to be ensured that the movement of the spray gun was at an adequate speed. This had to be done to make sure that the speed is sufficient enough to finish the painting job in a reasonable time and make sure speed is not too fast to make the paint job improper. Table 2 presented the experimental results of the time taken for the horizontal translation of a paint spray gun in contrast to the wall painting area. The results show that the larger the painting area is, the more time needed for the robot to fully paint the desired area.

Table 2. Time taken for horizontal translation

\begin{tabular}{cccc}
\hline $\begin{array}{c}\text { Test1: } \\
\text { Time taken } \\
\text { (seconds) }\end{array}$ & $\begin{array}{c}\text { Test 2: Time } \\
\text { taken } \\
\text { (seconds) }\end{array}$ & Average & $\begin{array}{c}\text { Distance } \\
\text { measured } \\
\text { (meters) }\end{array}$ \\
\hline 1.3 & 1.5 & 1.4 & 0.1 \\
3.5 & 3.3 & 3.4 & 0.2 \\
4.70 & 4.60 & 4.65 & 0.3 \\
5.30 & 5.70 & 5.50 & 0.4 \\
6.23 & 6.40 & 6.32 & 0.5 \\
8.56 & 8.01 & 8.3 & 0.6 \\
9.01 & 9.5 & 9.3 & 0.7 \\
10.70 & 10.50 & 10.6 & 0.8 \\
\hline
\end{tabular}


Figure 6 shows the time taken for the horizontal translation of the spraying gun, within 0.8 meters' distance. The spraying gun structure's speed is at a tolerable speed of roughly $0.07 \mathrm{~m} / \mathrm{s}$, which could be increased, but to provide high-quality painting without any gaps, current speed was selected as the most suitable without any harm to the working process. As well as for the horizontal translation, there was no acceleration done. The horizontal movement testing indicated that the paint spraying gun's overall horizontal movement was suitable. Current testing ensured that the painting process would run smoothly.

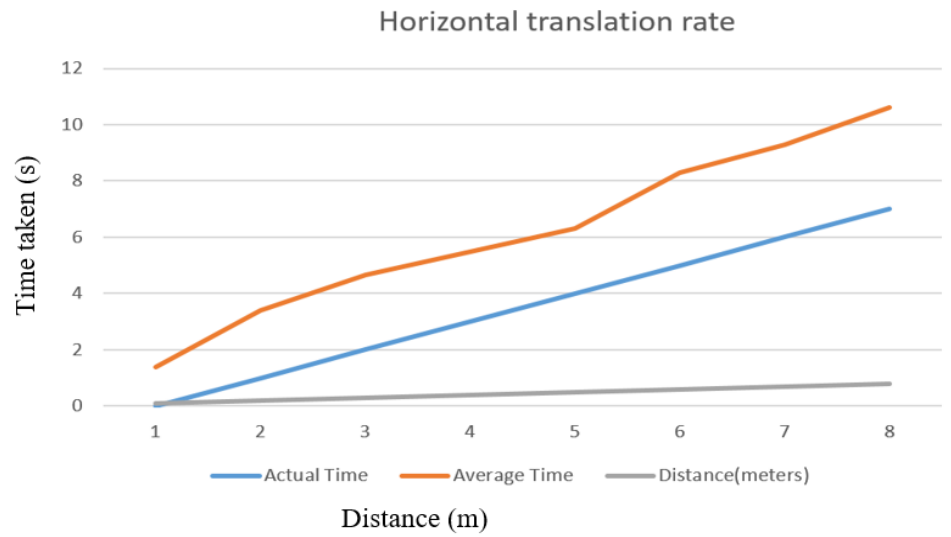

Figure 6. Time taken for horizontal translation

\subsection{Air compressor test}

Air compressor testing was done using water paint, paint spraying gun, air pressure valve connected to the Arduino UNO board and air compressor. The pressure was increased from an initial point of 40 psi with the step of 10 psi. The experiment aimed to describe which working air compressor pressure is the most suitable for the used spraying gun. Spraying gun was set in the initial position, and with each step of increasing the pressure, one layer was painted. Afterwards, the quality of the painted layer was examined manually to verdict the most appropriate psi level. Table 3 shows the experimental data collection of the air compressor test. This test demonstrates the relationship between the use of paint and the time needed on the exchange of air compressing pressure.

Table 3. Data collection for air compressor test

\begin{tabular}{ccc}
\hline $\begin{array}{c}\text { Air Pressure } \\
(\mathrm{psi})\end{array}$ & $\begin{array}{c}\text { Paint consumption } \\
(\mathrm{ml})\end{array}$ & $\begin{array}{c}\text { Time required } \\
(\mathrm{sec})\end{array}$ \\
\hline 40 & 4 & 14.71 \\
50 & 5 & 13.88 \\
60 & 22 & 12.64 \\
70 & 24 & 11.92 \\
80 & 26 & 11.14 \\
90 & 29 & 10.43 \\
100 & 33 & 9.75 \\
\hline
\end{tabular}

Figure 7 illustrates the relationship between paint consumption and time spend due to exchange of the air compressing pressure. The current graph's $\mathrm{X}$-axis represents the air pressure change rate within the range of 40-100 psi, and Y-axis represents the time rate from 0 to 35 seconds. As in Figure 7 of the air compressor test, the higher the air pressure, the less time required. However, paint consumption grows on the flipside. Due to the pressure created inside the paint tank of the spraying gun, paint is sprayed faster, which decreases the time needed for the painting process, but faster is not always better. If air pressure is too high, a layer of sprayed out paint will become too thick, which will cause leakages and other unwanted phenomena while painting process. As it is noticeable, at points of 40 and 50 psi, paint consumption is very low, comparing to the other pressure levels. It is caused by that fact that these air pressure levels were just not powerful enough to induce the paint spraying from the spray gun's nozzle.

IAES Int J Rob \& Autom, Vol. 10, No. 1, March 2021:68-74 


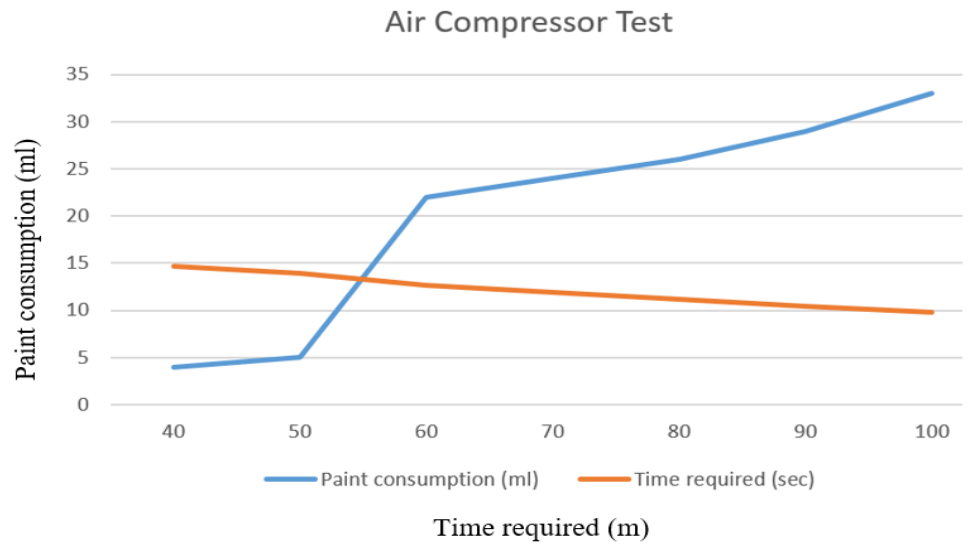

Figure 7. Data analysis of air compressor test

\subsection{Accuracy of the ultrasonic sensor}

During testing of automatic painting robot, the wall painter ultrasonic sensor was expected to work correctly with $100 \%$ accuracy, but like any other device, it has a range of errors. As even mentioned by the manufacturer, its error range is $\pm 3 \%$. However, while testing, it showed great performance with a minimum accuracy of $96 \%$. In the current robot's working process, it is vital to have accurate working ultrasonic sensors to provide equality in painting layers and make them straight, without any breakdowns on the edges and path endings.

\section{CONCLUSION}

The proposed research aims to construct an automatic robot, which will paint the buildings' walls of any size. The experimental results indicate that the proposed robot could smoothly paint the walls with an accuracy of up to $90 \%$ (spray gun accuracy) and in a very efficient time. Therefore, the system was developed with the option for the workers to select among several options to ensure that the prototype can be used for various heights. However, future development should be done to select any length according to the building's height. One further shortcoming is due to the capacity of the paint tank. The current system uses up to 1 litre of paint. This is inconvenient because the paint has to be filled by the workers' multiple times in some instances. The other shortcoming is due to the performance of the ultrasonic sensor used. The current ultrasonic sensor can work perfectly when used on a perpendicular wall; however, when painting edges, crevices and corners, the sensor can have inconsistencies in the readings. Therefore, this can further be improved by using more sensors that can enhance the results. The aforementioned shortcomings can be eliminated with further research and work.

\section{REFERENCES}

[1] I. Qadri, A. Muneer, and S. Mohamed Fati, "Automatic robotic scanning and inspection mechanism for mines using IoT," First International Conference on Electrical Energy and Power Engineering 2020 (ICEEPE 2020). pp.1-11, 2020.

[2] S. Al-Nabhani, and A. Muneer, "Automated library system using SMS based pick and place robot," International Journal of Computing and Digital Systems, vol. 8, no. 6, Nov. 2019.

[3] R. C. Luo, M. Hong, P. Chung, "Robot Artist for colorful picture painting with visual control system," 2016 IEEE/RSJ International Conference on Intelligent Robots and Systems IROS, pp. 2998-3003, 2016, doi: 10.1109/IROS.2016.7759464.

[4] P. Keerthanaa, K. Jeevitha, V. Navina, G. Indira, S. Jayamani, “Automatic wall painting robot,” International Journal of Innovative Research in Science, Engineering and Technology, vol. 2, no. 7, pp. 3009-3023, 2013.

[5] Abdellatif, "Design of an autonomous wall painting robot," Mechatronics and Robotics Dept. Egypt-Japan University of Science and Technology, 2012.

[6] Li Jing, S, "Automatic high rise walls painting robot: design and integration of spray painting system," Nanyang Technological University, 2016.

[7] Frederick P. Rivara MD. MPH, Diane C Thompson MS, "Prevention of falls in the construction industry: evidence for program effectiveness," American journal of preventive medicine, vol. 18, no. 4, pp. 23-26, May 2000.

[8] Geetha M. Waehrer, Xiuwen S. Dong, Ted Miller, Elizabeth Haile, Yurong Men, "Costs of occupational injuries in construction in the United States," Accident Analysis \& Prevention, vol. 39, no. 6, pp. 1258-1266, 2007. 
[9] Chia-Fen Chi, Tin-Chang Chang, Hsin-I Ting, "Accident patterns and prevention measures for fatal occupational falls in the construction industry," Applied Ergonomic, vol. 36, no. 4, pp. 391-400, 2005.

[10] Mohamed Sherif, "Safety climate in construction site environments," Journal of construction engineering and management, vol. 128, no. 5, pp.375-384, 2002.

[11] B. J. M. Ale, et al., "Accidents in the construction industry in the Netherlands: an analysis of accident reports using Storybuilder," Reliability Engineering \& System Safety, vol. 93, no. 10, pp. 1523-1533, 2008.

[12] Holly M. Johnson, Amarjit Singh, "Fall protection analysis for workers on residential roofs," Journal of Construction Engineering and Management, vol. 124, no. 5, pp.418-428, 1998.

[13] Mohamed T. Sorour, et al., "Development of roller-based interior wall painting robot," World Academy of Science, Engineering and Technology, vol. 59, pp. 1785-1792, 2011.

[14] U. S. Bureau of Labor Statistics, "Employer-reported workplace injuries and illnesses (Annual) news release," [Online]. Available: https://www.bls.gov/news.release/archives/osh_11092017. Htm, [Accessed 13 August 2020].

[15] R. Mukesh Kannan, P. Kishore, S. Rahul, K. Poomani, "Automatic paint spraying machine using IR sensor," International Journal of Trend in Research and Development (IJTRD), pp. 3-5, 2017.

[16] Juan Manuel Davila Delgado Lukumon Oyedele, et al., "Robotics and automated systems in construction: Understanding industry-specific challenges for adoption," Journal of Building Engineering, vol. 26, pp.100868, 2019.

[17] Ishak Bin Aris, A. K. M. Parvez Iqbal, "Design and fabrication of a Cartesian painter robot for the construction industry," International Journal of Mechanical Engineering Education, vol. 34, no, 2, pp.125-144. 2006.

[18] M. E. Helou, S. Mandt, A. Krause, P. Beardsley, "Mobile robotic painting of texture," 2019 International Conference on Robotics and Automation ICRA, 2019, doi: 10.1109/ICRA.2019.8793947.

\section{BIOGRAPHIES OF AUTHORS}

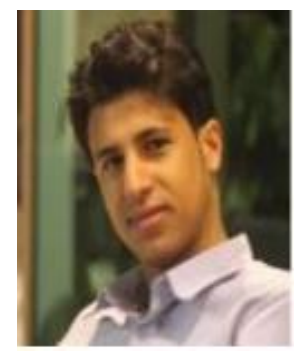

Amgad Muneer was born in Taiz, Yemen. He obtained his B. Eng degree (with honors) in Mechatronic Engineering from Asia Pacific University, Malaysia in 2018. He is currently pursuing the master's degree in information technology with Universiti Teknologi PETRONAS, Malaysia. His research interests focus on Image Processing, Machine Learning, Internet of Things, Machine Vision, Robotics and Automation. He has authored several ISI and Scopus journal/conference papers. He is a reviewer in some international impact-factor journals such as Journal of Combinatorial Optimization and several IGI global journals.

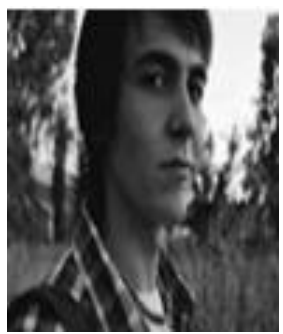

Zhan Dairabayev was born in Almaty, Kazakhstan. He acquired his B. Eng (2019) from Asia Pacific University of Technology and Innovation, Malaysia. His bachelor's degree was in Mechatronic Engineering. His research interests focus on Robotics and Automation, Security Systems, GSM communication tcechnology, Energy harvsting systems. 